\title{
Toward a Theory of Learned Hopefulness: A Structural Model Analysis of Participation and Empowerment
}

\author{
Marc A. Zimmerman \\ University of Michigan
}

\begin{abstract}
Two competing structural models were tested in an effort to develop a theory of learned hopefulness. Learned hopefulness suggests that empowering experiences-ones that provide opportunities to learn skills and develop a sense of control-can help individuals limit the debilitating effects of problems in living. Voluntary organizations are identified as natural settings that enable individuals to develop a sense of psychological empowerment. Empowerment was measured by cognitive, personality, and motivational measures of perceived control. Structural equation modeling was used to compare models for a sample of students and a sample of nonstudent community residents. The model which supports the theory of learned hopefulness included a direct effect of participation in voluntary organizations on psychological empowerment. An alternative model omitted the path between participation and empowerment. The learned hopefulness model reproduced the observed data with less error than the alternative model. The results provide support for a theory of learned hopefulness and suggest that future research to fully develop the theory is warranted. (c) 1990 Academic Press, Inc.
\end{abstract}

A review of the voluminous learned helplessness literature indicates that a great deal of attention has been paid to the psychological deficits that result from a perceived lack of control (Alloy, 1982; Garber \& Seligman, 1980; Roth, 1980). The basic learned helplessness paradigm is to expose individuals to uncontrollable conditions and then measure performance on subsequent tasks. Learned helplessness theory suggests that as individuals experience uncontrollable events they show performance deficits on subsequent tasks. This effect has been found in both experimental research (Hiroto \& Seligman, 1975; Benson \& Kennelly, 1976; Sherrod, Hage, Halpern, \& Moore, 1977; Jones, Nation, \& Massad,

I thank Deborah A. Salem, Julian Rappaport, Klaus Witz, Rhona Weinstein, and Ken Maton for their thoughtful comments on earlier drafts of this paper. Reprints of this article can be obtained by writing to Marc A. Zimmerman, Department of Health Behavior and Health Education, School of Public Health, University of Michigan, 1420 Washington Heights, Ann Arbor, MI 48109. 
1977) and field studies (Glass \& Singer, 1972; Metalsky, Abramson, Seligman, Semmel, \& Peterson, 1982). Seligman (1975, 1981) suggests that individuals who experience learned helplessness experience motivational and behavioral deficits, and emotional withdrawal.

Several investigators found that exposure to uncontrollable events facilitated rather than hindered performance (Roth \& Kobal, 1975; Hanusa \& Schulz, 1977; Tennen \& Eller, 1977). An attributional component was added to the original learned helplessness theory to account for the facilitation effects (Abramson, Seligman, \& Teasdale, 1978; Miller \& Norman, 1979). Individual attributions for the cause of uncontrollable events were proposed as mitigating factors for determining the impact of experiences and perceptions of uncontrollability. The modified theory predicts that individuals who attribute failure to stable, global, and internal factors will be more likely to exhibit learned helplessness than individuals with unstable, specific. and external attributions. Miller and Norman (1979) also included an individual's perception of the importance of the event and situational characteristics as factors that influence the effects of uncontrollable experiences.

The attributional model of learned helplessness is empirically supported. Peterson and Seligman (1984) reviewed research that used several different designs (e.g., longitudinal, field experiment, control group) and found support for the reformulated theory across studies. Brunstein and Olbrich (1985) found that the debilitating or facilitating effects of losing control were mediated by an individual's cognitive style. They found action-oriented individuals increased efforts to control while individuals who were more state dependent performed less well after exposure to uncontrollable events. Attributional style was also found to mediate learned helplessness effects for life insurance agents (Seligman \& Schulman, 1986), for generalizing the effect of uncontrollable experiences (Alloy, Abramson, Peterson, \& Seligman, 1984), and for self-reports of depression (Peterson, Bettes, \& Seligman, 1985; Metalsky et al., 1982). Nevertheless, the reformulation continues to focus on motivational, cognitive, and emotional deficits that may arise from a perceived lack of control.

\section{Learned Hopefulness}

An alternative approach to understanding the connection between perceived control and behavior is to focus on the positive consequences of exerting control. This is the idea of learned hopefulness. Learned hopefulness is the process of learning and utilizing problem-solving skills and the achievement of perceived or actual control. Learned hopefulness suggests that experiences that provide opportunities to enhance perceived control will help individuals cope with stress and solve problems in their 
personal lives. Perceived control is a primary variable in both learned helplessness and learned hopefulness theories.

Perceived control is multidimensional, but has typically been treated as a univariate construct. Psychologists have defined cognitive, personality, and motivational domains of perceived control and studied them independently (Zimmerman, 1986). Bandura (1982) suggests that selfefficacy theory is a cognitive component of perceived control. White (1959) and DeCharms (1968) presented the idea that motivation to control is a salient feature of perceived control theory. Locus of control has been identified as a personality component of perceived control (Rotter, 1966). Zimmerman and Rappaport (1988) found these three elements of perceived control formed one discriminant function that distinguished different types of citizens defined by their involvement in voluntary organizations and community activities. The multivariate function correlated positively with leadership and negatively with alienation. The function-defined by the shared variance of the three domains of perceived control-was identified as psychological empowerment. Psychological empowerment differs from perceived control because it is multidimensional and includes a theoretical link to community involvement.

Learned hopefulness is the process whereby individuals learn and utilize skills that enable them to develop a sense of psychological empowerment. The theory predicts that involvement in community organizations and activities is one way to both improve problem solving skills and enhance one's psychological empowerment (i.e., mastery and control over the environment). Several mediating factors may, however, influence the impact of participation. Participatory decision-making structures or the development of social support may enhance psychological empowerment. Conversely, frequent organizational failure or assignment of menial organizational tasks may hinder the development of empowerment. Nevertheless, learned hopefulness theory is initially supported if a direct effect is found between participation and one's sense of psychological empowerment.

Psychological empowerment is expected to be a product of learned hopefulness. As individuals gain control and mastery over their lives, and learn and utilize skills for influencing life events they become empowered (Rappaport, 1981; 1985). Skills can be learned through direct experience, observing others, or modeling behaviors (Bandura, 1982). Individuals may learn how to manage time, organize themselves, identify resource providers, work with others toward a common goal, or begin to understand the factors that influence decision making processes (Sue \& Zane, 1980) by participating in community organizations and activities. These skills may increase one's repertoire of personal coping strategies and social support, and help inoculate individuals against the debilitating 
consequences of life distress. The connection between skill building and coping has been established for social adjustment among children (Spivak $\&$ Shure, 1985), coping with divorced parents (Pedro-Carroll \& Cowen, 1985), and creative problem solving and job interview performance (Sarason \& Sarason, 1981). Seekins, Mathews, and Fawcett (1984) found that skill training can also enhance community leadership and decision making. One way for individuals to learn skills is from professionals in therapy (Bandura, Adams, Hardy, \& Howells, 1980) or workshop settings.

Alternatively, skills can be learned from fellow participants in natural settings such as mutual help groups (Rappaport, 1987) and other forms of voluntary citizen participation. These natural settings are fundamental to learned hopefulness theory because they are connected to community life and are not deficit-oriented or dependent on professional expertise. Participation differs from traditional skills training because it is initiated and controlled by grassroots leaders, offers opportunities to benefit from reciprocal helping (Maton, 1987), and provides settings for developing social support and a sense of community. Research on the individual effects of participation suggests that involvement in voluntary organizations enhances perceived control and reduces feelings of alienation (Levens, 1968; Zurcher, 1970; Langer \& Rodin, 1976; Rossi, 1982; Kieffer, 1984).

A comparison of the learned helplessness and learned hopefulness models are presented in Fig. 1. The experience of some event can lead to a lack of control or successful control. Individuals then make causal attributions for the event which results in an expectation about future events. When future events are expected to be uncontrollable, learned helplessness symptoms appear. The results are withdrawal, alienation, and depression. When future events are expected to be controllable, learned hopefulness characteristics appear. These include increased psychological empowerment, proactive behavior, and reduced alienation.

The present research uses structural equation modeling to test the hypothesis that involvement in community organizations has a positive and direct effect on psychological empowerment and both direct and indirect negative effects on feelings of alienation. Figure 2 represents two models of the relationship between participation, psychological empowerment, and alienation. Path $A$ is represented with a broken line to indicate that this path differs in the two models. The learned hopefulness model predicts that organizational involvement has a direct effect on psychological empowerment-path A is positive and points toward empowerment. The alternative model is one that predicts no direct path between participation and empowerment-path $A$ is omitted. The other paths remain the same in both models. Path B represents a negative 


\section{Learned Helplessneas Model}

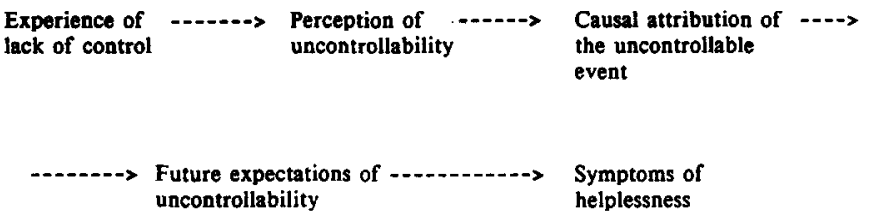

\section{Learned Hopefulness Model}

Experience of control control
Causal attribution of -...successful control
Future expectations

of control
Characteristics of hopefulness (psychological empowerment)

Fig. 1. Comparison of learned helplessness and learned hopefulness models. The learned helplessness model was adapted from Abramson. Seligman, and Teasdale (1978).

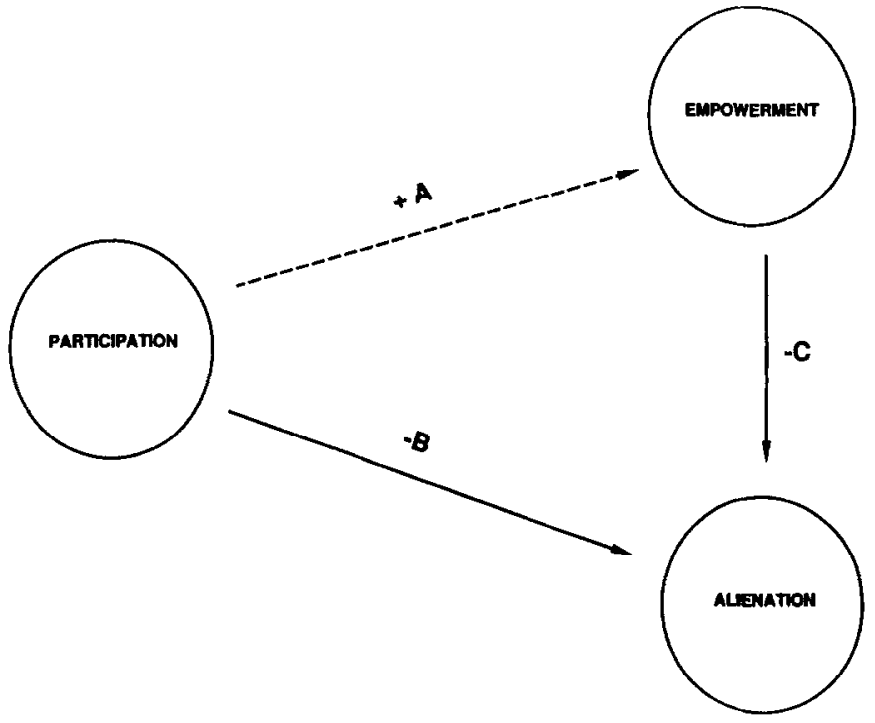

FIG. 2. Structural model of the relationship between participation, alienation, and psychological empowerment. 
relationship between participation and alienation. Path $\mathrm{C}$ represents a direct and negative influence of empowerment on alienation.

This study is a first step toward the development of a theory of learned hopefulness. It is necessary first to empirically test the hypothesis that participation has a direct and positive effect on psychological empowerment. If this hypothesis is supported then future research to investigate what specific skills are learned, how they are learned, and what conditions enhance or hinder the learning process would be warranted in order to more fully develop the theory. The model does not address individual attributions or why one experience may be perceived as controllable and another as uncontrollable. The research is designed only to test the most basic theoretical model of learned hopefulness. A basic assumption of the research is that organizational involvement is one way for individuals to exert control.

\section{METHOD}

\section{Research Participants}

Data were collected from two samples. The first sample consisted of undergraduate students $(N=388)$ who were required to participate in experiments as part of an introductory psychology course. The sample was predominantly white $(88 \%)$ and evenly distributed by gender. The mean age was $18.95(S D=1.64)$ and ranged from 16 to 39 years old. Forty-nine percent were freshmen and $51 \%$ were upperclassmen.

The second sample was comprised of nonstudent community residents $(N=205)$. The sample was predominantly white $(92 \%)$, married $(66 \%)$, and evenly divided by gender. The mean age was $41.9(S D=14.4)$ and ranged from 18 to 74 years old. Respondents were recruited at voluntary organization meetings. They were told that a $\$ 100$ donation would be made to the organization if $80 \%$ of them returned questionnaires. A group of nonparticipants were recruited from random digit dialing and were paid $\$ 5.00$ for their participation. They were screened to ensure they were not full-time students or members of any voluntary organization. The response rate for the voluntary organization members was $85 \%$ and it was $64 \%$ for the telephone sample.

\section{Procedure}

All data were collected using paper and pencil questionnaires. The students were asked to complete the questionnaires in groups of 30 to 40 during a scheduled 1-h session. Community residents were given the questionnaires at organizational meetings and completed them at home. They were supplied with stamped addressed envelopes for returning their questionnaires. The nonparticipant community residents were mailed a questionnaire after they agreed to participate in the study. They were also provided with stamped addressed envelopes for returning questionnaires.

Maximum likelihood estimation was used to test the structural models described in Fig. 2. This method was used rather than least-squares regression because theoretical constructs and measurement error can be represented in the model (Bentler, 1980). Theoretical models can also be represented by multiple mcasures. Structural cquation modeling addresses the problem of one-to-one correspondence for observed variables and theoretical constructs. Multivariate analysis also allows the measurement of variables to reflect the complexity of the theory. For example, empowerment is thought to be represented by a combination of personality. cognitive, and motivational measures of perceived control. 
Two models were compared. First, a partial model that did not include a path between participation and empowerment was tested (path $A$ was omitted). Second, a full model including path $A$ was analyzed. The partial model was compared to the full model in order to determine which model reproduced the observed data with the least amount of error. Bentler and Speckart (1979) used a similar procedure to test alternative models of the Fishbien-Ajzen attitude theory.

The theoretical (latent) variables were defined as participation, empowerment, and alienation. The observed (indicator) variables used to represent the latent variables are described below. The observed variable with the highest average correlation among each group of indicator variables was fixed at 1.0 in order to scale the latent variable and identify the model. The variables fixed at 1.0 were the same in both samples for the observed empowerment and alienation variables. Total attendance was fixed at 1.0 for the participation factor in the student sample and number of leadership positions held was fixed at 1.0 for the community sample.

\section{Indicator Variables}

Participation. Respondents were asked to list each voluntary organization in which they considered themselves members and to indicate the number of hours they volunteered each week and the number of months they have been involved for each organization. They also rated how often they attended organizational meetings on a 5-point Likert scale and listed any leadership positions held in each organization (e.g., president, treasurer, and committee chair). Individuals who were not members of any organizations were assigned a zero for all the participation variables.

Psychological empowerment. Four scales representing cognitive, personality, and motivational domains of perceived control were selected because they are psychometrically sound and contributed the most variance in its respective domain for distinguishing groups defined by amount of participation (Zimmerman \& Rappaport, 1988). The cognitive measures were internal political efficacy (Craig \& Maggiotto, 1982) and perceived competence (Florin \& Wandersman, 1984). The personality measure was internal locus of control (Levenson, 1974), and the motivational measure was desire for control (Burger \& Cooper, 1979). For the remainder of the paper, psychological empowerment will be referred to as empowerment for easier reading.

Alienation. An alienation scale that measured three different aspects of alienationpowerlessness, normlessness, and social isolation-was used (Dean, 1961). This scale was selected because it includes three subscales. showed adequate psychometric properties (Dean, 1961), and used a 5-point Likert format.

\section{RESULTS}

\section{Distribution of Observed Variables}

The means and standard deviations for the 11 observed variables for both samples are reported in Table 1. Most of the variables had ordinary variance structure. Only total number of hours and months were unusually distributed. This was expected because the nonparticipants would lower mean scores while increasing variance. Although, maximum likelihood estimates are robust against violations of multivariate normality (Joreskog \& Sorbom, 1984), log transformations of the data were analyzed. The factor loadings and path coefficients were slightly smaller than the original (nontransformed) data, but remained significant. The 
TABI.E 1

Means and Standard Deviations for the Observed Variables for the Student and Community Samples

\begin{tabular}{lrrrr}
\hline & \multicolumn{2}{c}{ Students } & & \multicolumn{2}{c}{ Community } \\
\cline { 2 - 3 } \cline { 4 - 5 } & $M$ & SD & & SD \\
\hline Empowerment & & & & \\
$\quad$ Internal political efficacy & 4.27 & 1.23 & 4.67 & 1.27 \\
Perceived competence & 2.79 & .56 & 2.77 & .53 \\
Desire for control & 5.04 & .63 & 4.98 & .64 \\
$\quad$ Internal locus of control & 4.62 & .52 & 4.54 & .58 \\
Alienation & & & & \\
$\quad$ Powerlessness & 2.87 & .50 & 2.75 & .57 \\
Normlessness & 2.91 & .58 & 2.46 & .68 \\
$\quad$ Social isolation & 3.03 & .52 & 2.88 & .53 \\
Participation & & & & \\
$\quad$ Hours per week & 16.25 & 34.60 & 17.25 & 23.40 \\
$\quad$ Months involved & 12.47 & 28.39 & 165.58 & 269.72 \\
$\quad$ Weekly attendance & 3.47 & 4.87 & 7.99 & 5.99 \\
$\quad$ Leadership positions & .33 & .81 & 1.74 & 2.29 \\
\hline
\end{tabular}

original data are presented in the results below in order to maintain the integrity of the observed data and to simplify the discussion.

\section{Measurement Model}

The results of the measurement model are presented in Table 2 . All indicator variables significantly load on their respective latent variables as hypothesized. The two samples have approximately equal loadings.

\section{Structural Model}

The latent variable path coefficients from the full structural model for the student sample are reported in Fig. 3. All paths are significant $(p<$ .05 ) and in expected directions. Significance levels are determined by dividing the parameter estimate by its standard error.

The full model path coefficients for the nonstudent sample are reported in Fig. 4. All paths are significant $(p<.05)$ for the nonstudent sample except the one from participation to alienation.

Table 3 presents the model fit test statistics for the full and partial models for both samples. All chi-square measures were significant $(p<$ .01 ), indicating a less than perfect fit of the model to the observed data. The goodness of fit index is a measure of the relative amount of variance and covariance accounted for in the model. It can range between 1.0 
TABLE 2

LiSRel Estimates of the Measurement Portion of the Full Structural Model for the Student (and Community) Sample

\begin{tabular}{lccr}
\hline & & Factor loadings & \\
\cline { 2 - 4 } Observed variables & Empowerment & Alienation & Participation \\
\hline Political efficacy & $.721(.644)$ & & \\
Competence & $.77(.953)$ & & \\
Desire & $1.00(1.00)$ & & \\
Internal locus & $.665(.518)$ & $1.00(1.00)$ & \\
Powerlessness & & $.686(.825)$ & $.689(.589)$ \\
Normlessness & & $.694(.607)$ & $.947(.905)$ \\
Social isolation & & & $1.00(.950)$ \\
Total hours & & & $.981(1.00)$ \\
Total months & & & \\
Attendance & & & \\
Leadership & & & \\
\hline
\end{tabular}

Note. Where no factor loading is indicated, the loading was fixed at zero. The 1.00 loadings were fixed at that level to identify the model. All parameters were significant $(p$ $<.01)$. Significance levels are determined by the parameter estimate divided by its standard error.

and zero; 1.0 indicates a perfect fit (Joreskog \& Sorbom, 1984). The full model for both samples have better goodness of fit measures than the partial model. The root mean square residual is the average difference between the observed correlations and the correlations estimated by the model. The data are reproduced with less error using the full model for

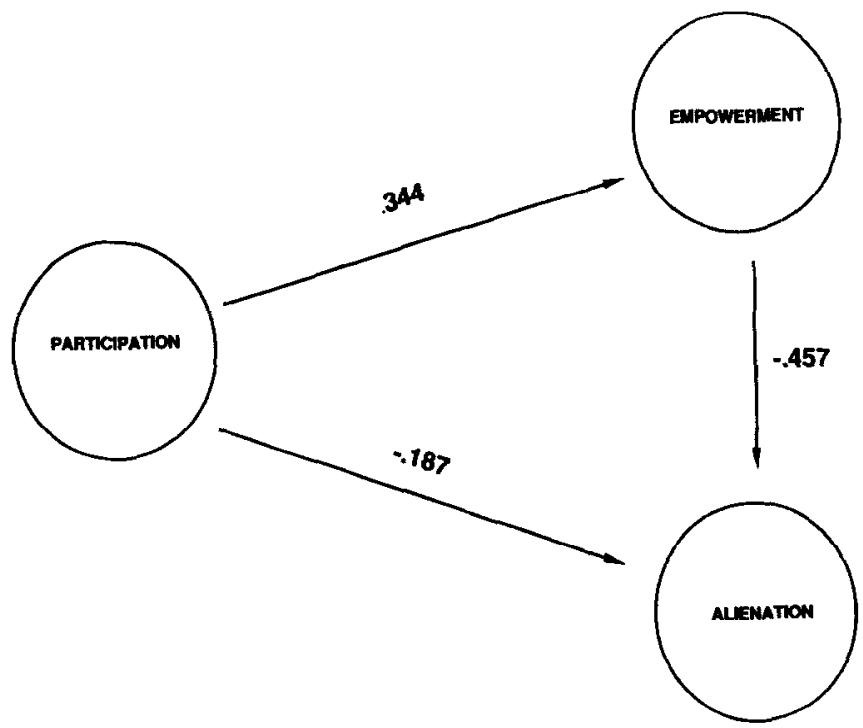

FIG. 3. Latent variable full structural model for the student sample. 


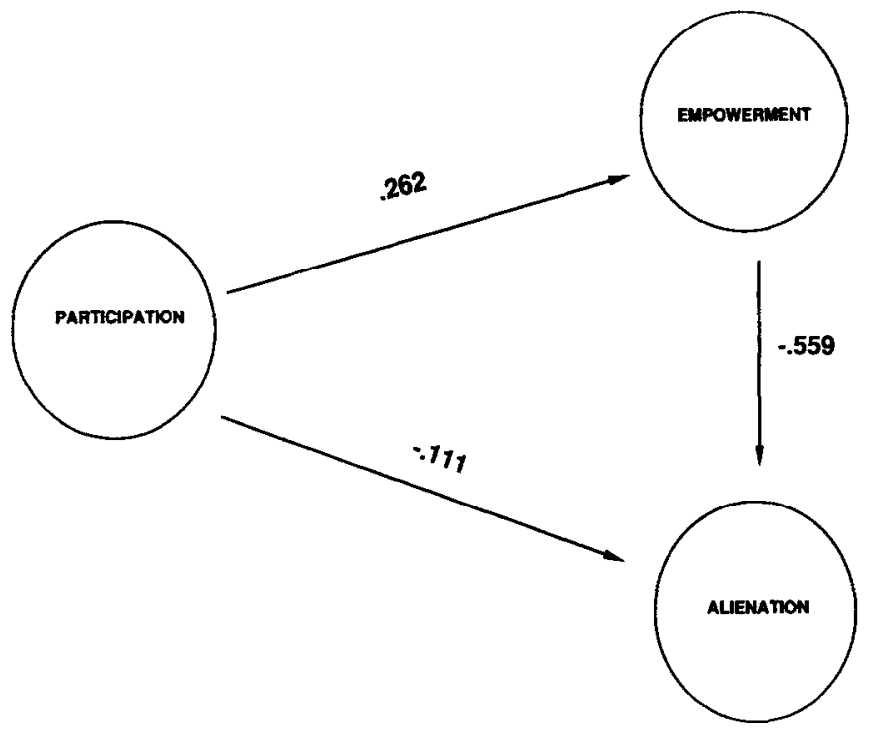

FIG. 4. Latent variable full structural model for the community sample.

both samples. The percentage of variance accounted for refers to the total variance of the latent variable path model. The model that includes the path between participation and empowerment more than doubles the amount of explained variance in the model for the student sample and it more than triples in the nonstudent sample.

\section{DISCUSSION}

The results provide initial support for a theory of learned hopefulness. They suggest that participation in community organizations has a direct

TABLE 3

Model Fit Assessment Statistics for Both Models and Samples

\begin{tabular}{lccccc}
\hline & \multicolumn{2}{c}{ Students } & \multicolumn{2}{c}{ Community } \\
\cline { 2 - 3 } \cline { 2 - 3 } & $\begin{array}{c}\text { Partial } \\
\text { model }\end{array}$ & $\begin{array}{c}\text { Full } \\
\text { model }\end{array}$ & $\begin{array}{c}\text { Partial } \\
\text { model }\end{array}$ & $\begin{array}{c}\text { Full } \\
\text { model }\end{array}$ \\
\hline$\chi^{2}$ & 146.83 & 119.60 & 129.58 & 119.46 \\
& $(d f=42)$ & $(d f=41)$ & $(d f=42)$ & $(d f=41)$ \\
$\begin{array}{l}\text { Goodness of fit index } \\
\text { Root mean square } \\
\text { residual }\end{array}$ & .939 & .948 & .898 & .905 \\
$\begin{array}{l}\text { \% variance explained } \\
\text { by structural model }\end{array}$ & .099 & .048 & .100 & .081 \\
\hline
\end{tabular}

Note. The partial model excludes the path from participation to empowerment in the structural model. The full model includes this path. 
and positive effect on psychological empowerment. This finding is a substantive first step in the development of a theory of learned hopefulness even though causality is not directly tested. Confidence in the results is strengthened by replication across two samples. An analysis of the model fit indices indicates that the full (learned hopefulness) model represents the data with less error than the partial model. The model with a direct effect of participation on empowerment reduces the $\chi^{2}$ by an amount much larger than the decrease in degrees of freedom. This suggests a considerable improvement in the model (Bentler \& Speckart, 1979; Joreskog \& Sorbom, 1984). Other fit indices-root mean square residual, goodness of fit index, and variance explained-also suggest that the learned hopefulness model provides a better fit of the data than the partial model.

The fact that the structural model reproduced the data with some error may be partly due to the restricted range of several of the observed variables. The means for each of the indicator variables for empowerment and alienation are all above the middle score for the measure and the standard deviations are small. Restricted range can attenuate the variance explained by a set of variables (Pedhazur, 1982). The $\chi^{2}$ tests for both models also suggest a poor fit, but Joreskog and Sorbom (1984) point out that this statistic may not be a valid test of a structural model when large sample sizes are used and when the observed data deviates from multivariate normality (two conditions of the data reported here). Although maximum likelihood estimation is robust against violations of multivariate normality, skewed distributions of the observed variables could contribute to an inflated $\chi^{2}$ statistic (Joreskog \& Sorbom, 1984). The moderate level of fit may also be due to the fact that empowered individuals are probably predisposed to participate. Examination of the influence of participation on the development of psychological empowerment must ultimately be studied using longitudinal and experimental designs.

Mediating factors that were not measured in this study may also explain mispecifications in the full model. Participation may lead to empowerment only under certain circumstances. For example, organizations that encourage members to participate in decision making and to assume responsibility are expected to enhance psychological empowerment while less participatory organizations may not be as empowering. Another mediating variable may be social support. Maton and Rappaport (1984) found that social identity and sense of community were components of empowerment for members of a church organization. Organizations that foster interaction and mutual help are expected to be more empowering than those that do not require working with others to achieve organizational goals. The specific skills learned or used during participation 
may also mitigate the relationship between participation and empowerment. Skills that help individuals solve problems, identify resources, and recognize factors that influence decisions may prepare participants to successfully exert personal control. Skills such as record keeping and addressing envelopes may be less beneficial. Research that distinguishes between types of involvement and organizational structures will help elucidate the effects of participation.

The results suggest that one's sense of empowerment plays a stronger role than participation in reducing alienation. Participation reduced alienation directly only for the student sample, but the effect was larger for the path between empowerment and alienation. The indication that empowerment has a mediating effect on alienation reinforces the idea of learned hopefulness. Personal feelings of control are expected to reduce perceptions of powerlessness, normlessness, and isolation.

Demographic characteristics such as socioeconomic status (SES), gender, and age may provide alternative explanations for the relationship found between participation and empowerment. Past research, however, suggests this is not the case. For example, Zimmerman and Rappaport (1988) found the relationship between participation and empowerment remained after age and SES were covaried. Zurcher (1970) found lower SES individuals showed the greatest gains in perceived control after participating while other SES groups reported less improvement. Levens (1968) found participants in a welfare rights organization reported a greater sense of perceived control than nonparticipants. It appears that the relationship between participation and empowerment is not solely determined by individual demographic characteristics.

Theories similar to learned hopefulness have been posited before (Rosenbaum, 1980; Rosenbaum \& Ben-Ari, 1985; Gregory, Chartier, \& Wright, 1979). Rosenbaum (1980) introduced a theory of learned resourcefulness (LR). LR, an extension of the self-control literature, includes self-instructions to cope with emotional trauma, delay of gratification, and the belief that one can regulate internal (intrapsychic) events. LR also focuses on the regulation of negative internal events (e.g., low mood states). In contrast, learned hopefulness is not limited to cognitive skills and behavioral self-control, but also includes proactive behavior and motivation. Learned hopefulness also concerns interactions in the social and political environment (i.e., external events) and focuses on positive outcomes (e.g., psychological empowerment). Gregory et al. (1979) present the idea of learned effectiveness. They found that individuals with an external locus of control improved their performance when they were given opportunities to experience successful control. This result is consistent with learned hopefulness, but is more limited because it refers only to individuals with an external locus of control 
and to performance of specific tasks. Other investigators have found that performance deficits may be reduced if individuals learn skills to cope with seemingly uncontrollable experiences (e.g., Coyne, Metalsky, \& Lavelle, 1980; Altmaier \& Happ, 1985). These alternative theories are similar to learned hopefulness because they suggest that personal skills may inoculate individuals from the debilitating effects of uncontrollability.

Learned hopefulness also builds on self-efficacy theory. The model refers to the consequences of experiencing a controllable event; includes personality, motivational, and cognitive components; and is specifically connected to action in the public domain. Self-efficacy is considered a cognitive theory (Bandura, 1982) and is not necessarily related to involvement in community organizations and activities. Self-efficacy theory has also been researched primarily in therapeutic settings or with professional involvement in efficacy training. Learned hopefulness suggests that one can become efficacious or empowered without professional involvement.

This study suggests that future research on learned hopefulness theory is warranted and holds promise as a counterpart to learned helplessness theory. The current study was designed only to test the theory in its most rudimentary form and in one context. One goal for future research is to develop a self-report scale of learned hopefulness. This scale could measure one's ability to apply skills learned in one setting to other life domains and confidence and willingness to exert control. The next step is to specify the settings and opportunities necessary for the development of psychological empowerment. This research provides a theoretical framework and an empirical basis for shifting our research focus from the negative consequences of uncontrollability to understanding the positive consequences of successful efforts to exert control.

\section{REFERENCES}

Abramson, L. Y., Seligman, M. E. P., \& Teasdale, J. D. (1978). Learned helplessness in humans: Critique \& reformulation. Journal of Abnormal Psychology, 87, 49-74.

Alloy, L. B. (1982). The role of perceptions and attributions for response outcome noncontingency in learned helplessness: A commentary and discussion. Journal of Personality, 50, 443-479.

Alloy, L. B., Abramson, L. Y., Peterson, C., \& Seligman, M. E. P. (1984). Attributional style and the generality of learned helplessness. Journal of Personality and Social Psychology, 46, 681-687.

Altmaier, E. M., \& Happ, D. A. (1985). Coping skills training's immunization effects against learned helplessness. Journat of Social and Clinical Psychology, 3, 181-189.

Bandura, A. (1982). Self-efficacy mechanism in human agency. American Psychologist, $37,122-147$.

Bandura, A., Adams, N. E., Hardy, A: B., \& Howells, G. N. (1980). Tests of generality of self-efficacy theory. Cognitive Research and Therapy, 4, 39-66. 
Benson, J. S., \& Kennelly, K. J. (1976). Learned helplessness: The result of uncontrollable reinforcements or uncontrollable aversive stimuli? Journal of Personality and Social Psychology, 34, 138-145.

Bentler, P. M. (1980). Multivariate analysis with latent variables: Causal modeling. Annual Review of Psychology, 31, 419-456.

Bentler, P. M., \& Speckart, G. (1979). Models of attitude-behavior relations. Psychological Review, 86, 452-464.

Brunstein, J. C., \& Olbrich, E. (1985). Personal helplessness and action control: Analysis of achievement related cognitions, self-assessments, and performance. Journal of Personality and Social Psychology, 48, 1540-1551.

Burger, J. M.. \& Cooper, H. M. (1979). The desirability of control. Motivation and Emotion, 3, 381-393.

Coyne, J. C., Metalsky, G. I., \& Lavelle, T. L. (1980). Learned helplessness as experimenter-induced failure and its alleviation with attentional redeployment. Journal of Abnormal Psychology, 89, 350-357.

Craig. S. C., \& Maggiotto, M. A. (1982). Measuring political efficacy. Political Methodology, 8, 85-109.

Dean, D. G. (1961). Alienation: Its meaning and measurement. American Sociological Review, 26, 753-758.

DeCharms, R. (1968). Personal causation. New York: Academic Press.

Florin, P., \& Wandersman, A. (1984). Cognitive social learning and participation in community development. American Journal of Community Psychology, 12, 689-708.

Garber, J., \& Seligman, M. E. P. (1980). Human helplessness: Theory and application. New York: Academic Press.

Glass, D. C., \& Singer, J. E. (1972). Urban stress: Experiments on noise and social stressors. New York: Academic Press.

Gregory, W. L., Chartier, G. M., \& Wright, M. H. (1979). Learned helplessness and learned effectiveness: Effects of explicit response cues on individuals differing in personal control expectancies. Journal of Personality and Social Psychology. 37, 19821992.

Hanusa, B. H., \& Schulz, R. (1977). Attributional mediators of learned helplessness. Journal of Personality and Social Psychology, 35, 602-611.

Hiroto, D. S., \& Seligman, M. E. P. (1975). Generality of learned helplessness in man. Journal of Personality and Social Psychology, 31, 311-322.

Jones, S. L., Nation, J. R., \& Massad, P. (1977). Immunization against learned helplessness in man. Journal of Abnormal Psychology, 86, 75-84.

Joreskog, K. G., \& Sorbom, D. (1984). LISREL VI: Analysis of linear structural relationships by the method of maximum likelihood. Mooresville, IN: Scicntific Software. Inc.

Kieffer, C. (1984). Citizen empowerment: A developmental perspective. Prevention in Human Services, 3, 9-36.

Langer, E. J., \& Rodin, J. (1976). The effects of choice and enhanced personal responsibility for the aged: A field experiment in an institutional setting. Journal of Personality and Social Psychology, 34, 191-198.

Levens, H. (1968). Organizational affiliation and powerlessness: A case study of the welfare poor. Social Problems, 16, 18-32.

Levenson, H. (1974). Activism and powerful others: Distinctions within the concept of internal-external control. Journal of Personality Assessment, 38, 377-383

Maton, K. I. (1987). Patterns and psychological correlates of material support within a religious setting: The bi-directional support hypothesis. American Journal of Community Psychology, 15, 185-207. 
Maton, K. I., \& Rappapor, J. (1984). Empowerment in a religious setting: A multivariate investigation. Prevention in Human Services, 3, 37-72.

Metalsky, G., Abramson, L. Y., Seligman, M. E. P., Semmel, A., \& Peterson, C. (1982). Attributional styles and life events in the classroom: Vulnerability and invulnerability to depressive mood reactions. Journal of Personality and Social Psychology, 43, 612617.

Miller, I., \& Norman, W. (1979). Learned helplessness in humans: A review and attribution theory model. Psychological Bulletin, 86, 93-118.

Pedhazur, E. J. (1982). Multiple regression in behavioral research (2nd ed.). New York: Holt, Rinehart \& Winston.

Pedro-Carroll, J. L., \& Cowen, E. L. (1985). The children of divorce intervention program: An investigation of the efficacy of a school-based prevention program. Journal of Consulting and Clinical Psychology, 53, 603-611.

Peterson, C., Bettes, B. A., \& Seligman, M. E. P. (1985). Depressive symptoms and unprompted causal attributions: Content analysis. Behavior Research and Therapy. 23, 379-382.

Peterson, C., \& Seligman, M. E. P. (1984). Causal explanations as a risk factor for depression: Theory and evidence. Psychological Review, 91, 347-374.

Rappaport, J. (1981). In praise of paradox: A social policy of empowerment over prevention. American Journal of Community Psychology, 9, 1-25.

Rappaport, J. (1985). The power of empowerment language. Social Policy, 16, 15-21.

Rappaport, J. (1987). Terms of empowerment/exemplars of prevention: Toward a theory for community psychology. American Journal of Community Psychology, 15, 121148.

Rosenbaum, M. (1980). Learned resourcefulness as a behavioral repertoire for the selfregulation of internal events: Issues and speculations. In M. Rosenbaum \& C. M. Franks (Eds.), Perspectives on behavior therapy in the eighties (pp. 54-73). New York: Springer.

Rosenbaum, M., and Ben-Ari, K. (1985). Learned helplessness and learned resourcefulness: Effects of noncontingent success and failure on individuals differing in self-control skills. Journal of Personality and Social Psychology, 48, 198-215.

Rossi, A. S. (1982). Feminists in politics. New York: Academic Press.

Roth, S. (1980). A revised model of learned helplessness in humans. Journal of Personality, 48, 103-133.

Roth, S., \& Kobal, L. (1975). The effects of noncontingent reinforcement on tasks of differing importance: Facilitation and learned helplessness effects. Journal of Personality and Social Psychology, 32, 680-691.

Rotter, J. (1966). Generalized expectancies for internal versus external control of reinforcement. Psychological Monographs, 80, 1-28.

Sarason, I. G., \& Sarason, B. R. (1981). Teaching cognitive and social skills to high school students. Journal of Consulting and Clinical Psychology, 49, 908-918.

Seekins, T., Mathews, M., \& Fawcett, S. B. (1984). Enhancing leadership skills for community self-help organizations through behavioral instruction. Journal of Community Psychology, 12, 155-163.

Seligman, M. E. P. (1975). Helplessness. San Francisco: W. H. Freeman.

Seligman, M. E. P. (1981). A learned helplessness point of view. In L. Rehm (Ed.), Behavior therapies for depression. New York: Academic Press.

Seligman, M. E. P., \& Schulman, P. (1986). Explanatory style as a predictor of productivity and quitting among life insurance sales agents. Journal of Personality and Social Psychology, 50, 832-838.

Sherrod, D. R., Hage, J. N., Halpern, P. L., \& Moore, B. S. (1977). Effects of personal 
causation and perceived control on responses to an adverse environment: The more control the better. Journal of Experimental Social Psychology, 13, 14-27.

Spivak, G., \& Shure, M. B. (1985). ICPS and beyond: Centripital and centrifugal forces. American Journal of Community Psychology, 13, 226-243.

Sue, S., \& Zane, N. (1980). Learned helplessness theory and community psychology. In M. S. Gibbs, J. R. Lachemeyer, \& J. Sigal (Eds.), Community psychology: Theoretical and empirical approaches (pp. 121-143). New York: Gardener Press.

Tennen, H., \& Eller, S. (1977). Attributional components of learned helplessness and facilitation. Journal of Personality and Social Psychology, 35, 265-271.

White, R. W. (1959). Motivation reconsidered: The concept of competence. Psychological Review, 66, 297-333.

Zimmerman, M. A. (1986). Citizen participation, perceived control, and psychological empowerment. Unpublished doctoral dissertation, University of Illinois, Champaign.

Zimmerman, M. A., \& Rappaport, J. (1988). Citizen participation, perceived control, and psychological empowerment. American Journal of Community Psychology, 16, 725750 .

Zurcher, L. A. (1970). The poverty board: Some consequences of "Maximum Feasible Participation." Journal of Social Issues, 26, 85-107. 